\title{
Smart Modular Helmet with an Innovative Information Relaying System ${ }^{\dagger}$
}

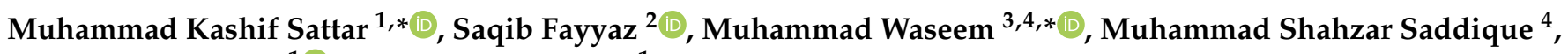 \\ Muhammad Usama ${ }^{1}$ and Hassan Bin Ilyas ${ }^{1}$
}

1 Department of Electrical Engineering, HITEC University, Taxila 47070, Pakistan; m.usamasaleem0007@gmail.com (M.U.); hassanilyas3406@gmail.com (H.B.I.)

2 Department of Electrical, Government College of Technology (GCT), Rawalpindi 46000, Pakistan; saqib_fayyaz@outlook.com

3 School of Electrical Engineering, Zhejiang University, Hangzhou 310027, China

4 Department of Electrical Engineering, University of Engineering and Technology (UET), Taxila 47080, Pakistan; shahzar613@gmail.com

* Correspondence: kashif.sattar@hitecuni.edu.pk (M.K.S.); mwaseem@zju.edu.cn (M.W.)

+ Presented at the 1st International Conference on Energy, Power and Environment, Gujrat, Pakistan, 11-12 November 2021

Citation: Sattar, M.K.; Fayyaz, S.;

Waseem, M.; Saddique, M.S.; Usama, M.; Ilyas, H.B. Smart Modular

Helmet with an Innovative Information Relaying System. Eng. Proc. 2021, 12, 94. https://doi.org/ 10.3390/engproc2021012094

Academic Editor: Qasim Awais

Published: 26 January 2022

Publisher's Note: MDPI stays neutral with regard to jurisdictional claims in published maps and institutional affiliations.

Copyright: (C) 2022 by the authors. Licensee MDPI, Basel, Switzerland. This article is an open access article distributed under the terms and conditions of the Creative Commons Attribution (CC BY) license (https:// creativecommons.org/licenses/by/ $4.0 /)$.

\begin{abstract}
Road accidents are a common occurrence throughout the world. The development of efficient electric vehicle (EVs) with high levels of safety is one of today's biggest challenges. In this article, a novel modular bike helmet based on an RF transmitter and a helmet side based on Arduino Uno, an accelerometer and an LED array that can relay information to approaching vehicles has been proposed. Current motorbike helmets are a form of passive protective gear that only serve the purpose of avoiding fatal damage to the skull. The proposed helmet will add to the current functionality of a helmet by making it smarter, giving it a means of preventing an accident. The proposed helmet will broadcast information about the biker's movements, such as acceleration and deceleration, to the approaching vehicles. This information has never been broadcasted to approaching vehicle before. Additionally, common turn and stop signals will be broadcasted, allowing the driver of any approaching vehicle to take informed decision that can ensure both their safety and that of the biker.
\end{abstract}

Keywords: Arduino Uno; RF communication; control system

\section{Introduction}

Road accidents are a common occurrence throughout the world. Be it a developed country or an underdeveloped country, traffic accidents on roads seem inevitable. It has been observed that among the total roadside accidents in year 2016, the highest percentage of fatalities seen per hundred million vehicle miles traveled was for motorcycles. The data in this study were taken from the US department of transportation and they indicated that the fatality rate in motorcycle crashes is $25.85 \%$, which is much higher than for light truck or passenger vehicles, which have fatality rates of $0.73 \%$ and $0.93 \%$, respectively [1]. The motorcycle is a sophisticated machine that requires full presence of mind and a high level of skill for effective operation, and yet despite the skills required of the driver, it does not impress us in road safety. Any misuse, such as speeding, can be fatal [2]. On road, motorcycles are under threat, not only from hurdles on the road, but also from other careless drivers. One careless move by the inattentive driver of an approaching vehicle can be fatal. The current means used to keep the approaching vehicle aware of the motorcycle moving in front of it are hampered by the lack of the complete transfer of information. Brake lights, for example, indicate that the biker has pressed the brake, but during gear braking or acceleration, no indication is relayed to the approaching vehicle. The bike's turning indicators are an effective information-relaying device, but if the approaching 
vehicle is too fast or if it is too close to the bike, or if the weather is bad, they can be overlooked. To overcome this difficulty and to broadcast more information to approaching vehicles, researchers have delved deep and looked for innovative means. One means of relaying more information to approaching vehicles is to make the helmet smart. A common motorcycle helmet is a protective shell that serves to protect the rider's head in case of any impact. Traditional helmets are not information-relaying devices. Attempts have been made to make these protective helmets smart and add to their functionality. In [3], the focus was on the proper installation of the helmet and the prevention of speeding; in [4], an internet of things-based helmet was proposed that autonomously initiates an emergency response in case of any accident; in [5], a novel video processing-based setup was integrated along with a camera to relay information to the biker about fast approaching vehicles from their blind side; in [6], a smart helmet was proposed that detects obstacles and informs the emergency services in case of accidents through GSM [7], and this helmet also alerts the authorities in case of alcohol use; in [8], a helmet was integrated with a Bluetooth module, enabling it to connect to a smart phone and receive calls or play music, with the main objective being to encourage the use of helmets by making them smart; in [9], a wear-proof helmet was proposed that had an information-relaying system in case of accidents; and in [10], a modular smart helmet with a vehicle and biker side was proposed. All these proposed helmets added to the functionality of the basic helmet, but did not address the problem of relaying information to the approaching vehicle. In this article, we propose a modular smart helmet with a bike side based on an RF transmitter and a helmet side based on Arduino Uno, an accelerometer and an LED array that will serve as an information-relaying system that can communicate with an approaching vehicle.

\section{Proposed System}

The proposed system consists of two separate modules, namely, the bike module and the helmet module. A block diagram of the bike module is shown in Figure 1. The bike module consists of only a $433 \mathrm{MHz}$ RF transmitter. The reason to keep the bike module as minimal as possible is its ease of installation and hassle-free repair. The RF transmission has four control options. Two control signals are taken from the indicator and one from the brake light. The fourth signal is used to enable or disable the helmet features.

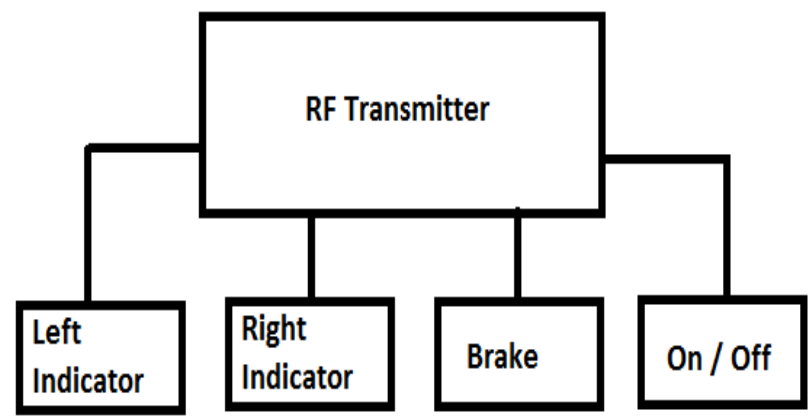

Figure 1. Block diagram (bike module).

The block diagram of the helmet module is shown in Figure 2. The helmet module is powered by a rechargeable power source mounted on the helmet and it operates under the following modes. On/off: During off mode, the RF signal receiver cuts off supply to control unit, accelerometer and LED array using a transistor as a switch controlled by the RF receiver toggle input received from the bike module. Uniform movement: During uniform movement, the control unit indicates only the left and right turn indicators on the LED array whenever the RF receiver receives the respective control signals from the bike. Non-uniform movement: During non-uniform movement, the motion control unit reads a signal from the accelerometer that enables it to identify whether the bike is accelerating or decelerating. This acceleration or deceleration is indicated on the LED array to inform the approaching vehicle. Currently, bikes lack the means to present this information and 
can only indicate braking or turning decisions. Braking: During braking, the control unit indicates the brake operation on the LED array whenever the RF receiver receives the respective control signals from the bike.

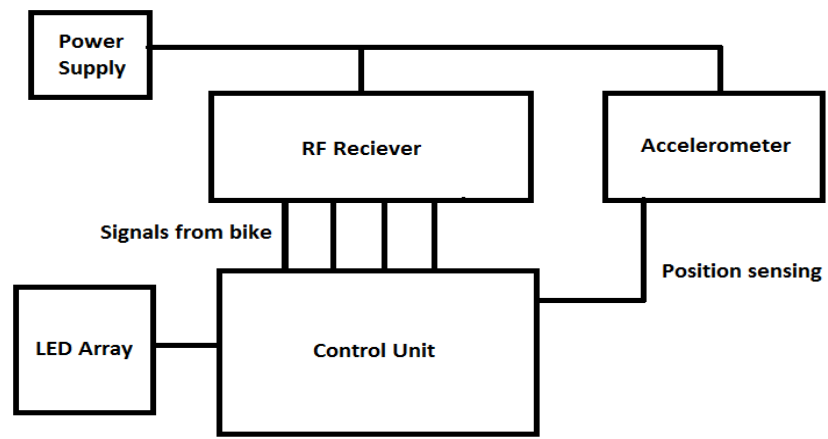

Figure 2. Block diagram (helmet module).

\section{Proposed Hardware}

Bike module: The only external component in the bike module is a four-channel RF module.

Helmet module: The helmet module contains the following parts:

A power supply: The power requirements of the helmet module are satisfied by two 3.7 V $4200 \mathrm{mAH}$ lithium cells. They can be easily charged by an off-the-shelf charging circuit, as shown in Figures 3 and 4 depicted the RF receiver.

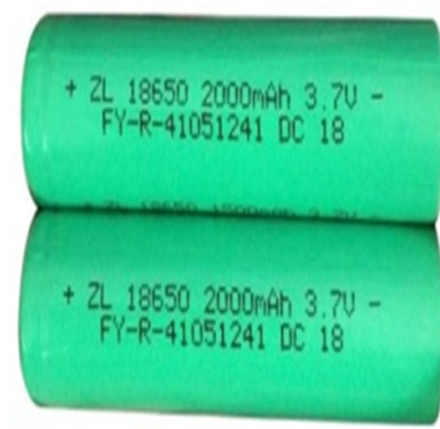

Figure 3. Power supply.

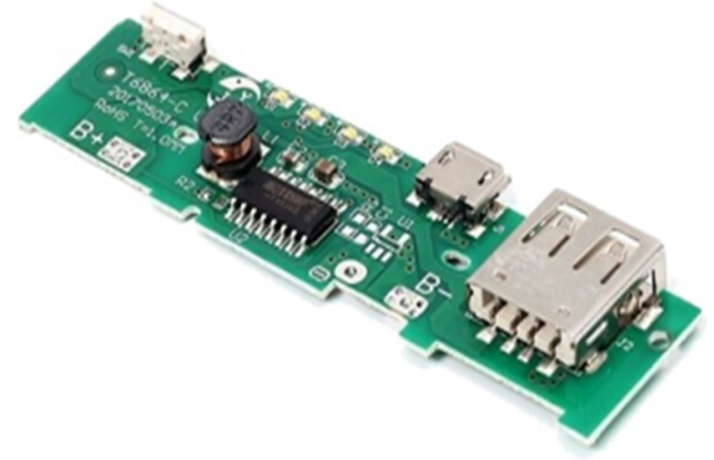

Figure 4. RF receiver.

An accelerometer: The accelerometer is an ADXL335 unit, shown in Figure 5. It is used to sense the acceleration or deceleration of the bike and relay this information to the control unit. 


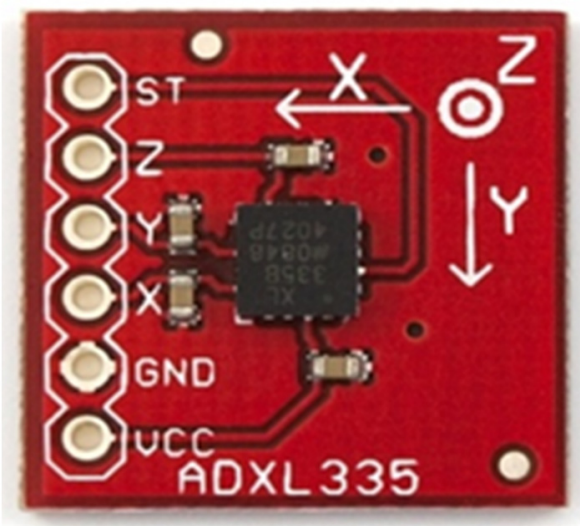

Figure 5. Accelerometer.

LED array (matrix): Two $8 \times 8$ led dot matrices, along with their LED driver, Max7219 IC, are used to display the information shown in Figure 6.

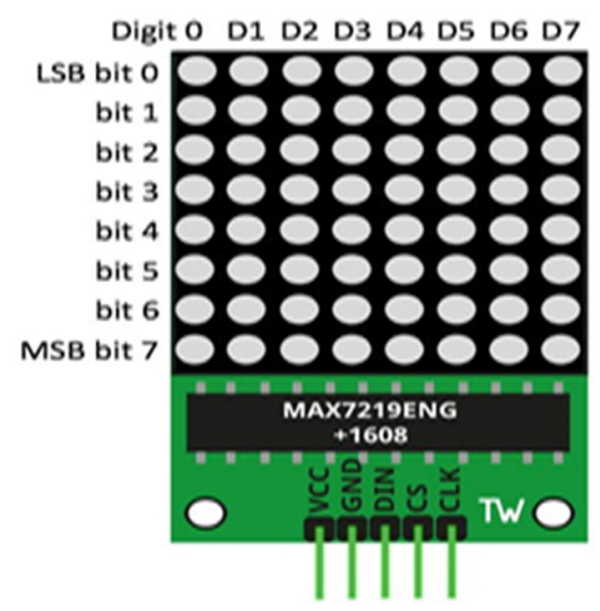

Figure 6. LED array.

Control unit: The control unit in the helmet module is based on an Arduino Uno controller, shown in Figure 7. The Arduino Uno interprets the signals received from the RF receiver and accelerometer and displays the necessary information for approaching traffic. The circuit connection diagram is shown in Figure 8, and the logic flow diagram is shown in Figure 9.

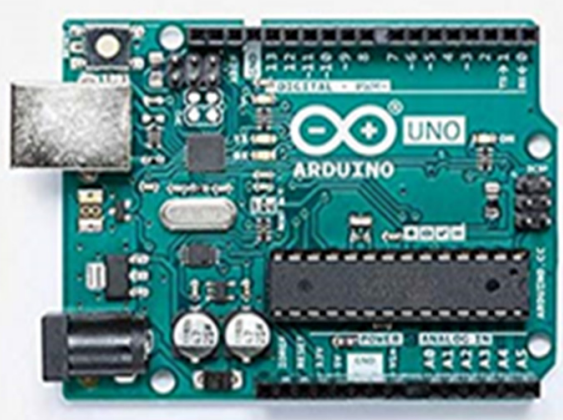

Figure 7. Arduino Uno. 


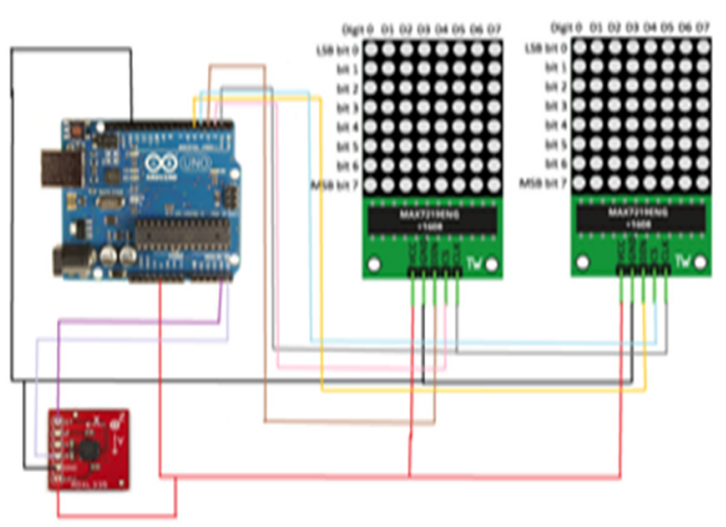

Figure 8. Control unit.

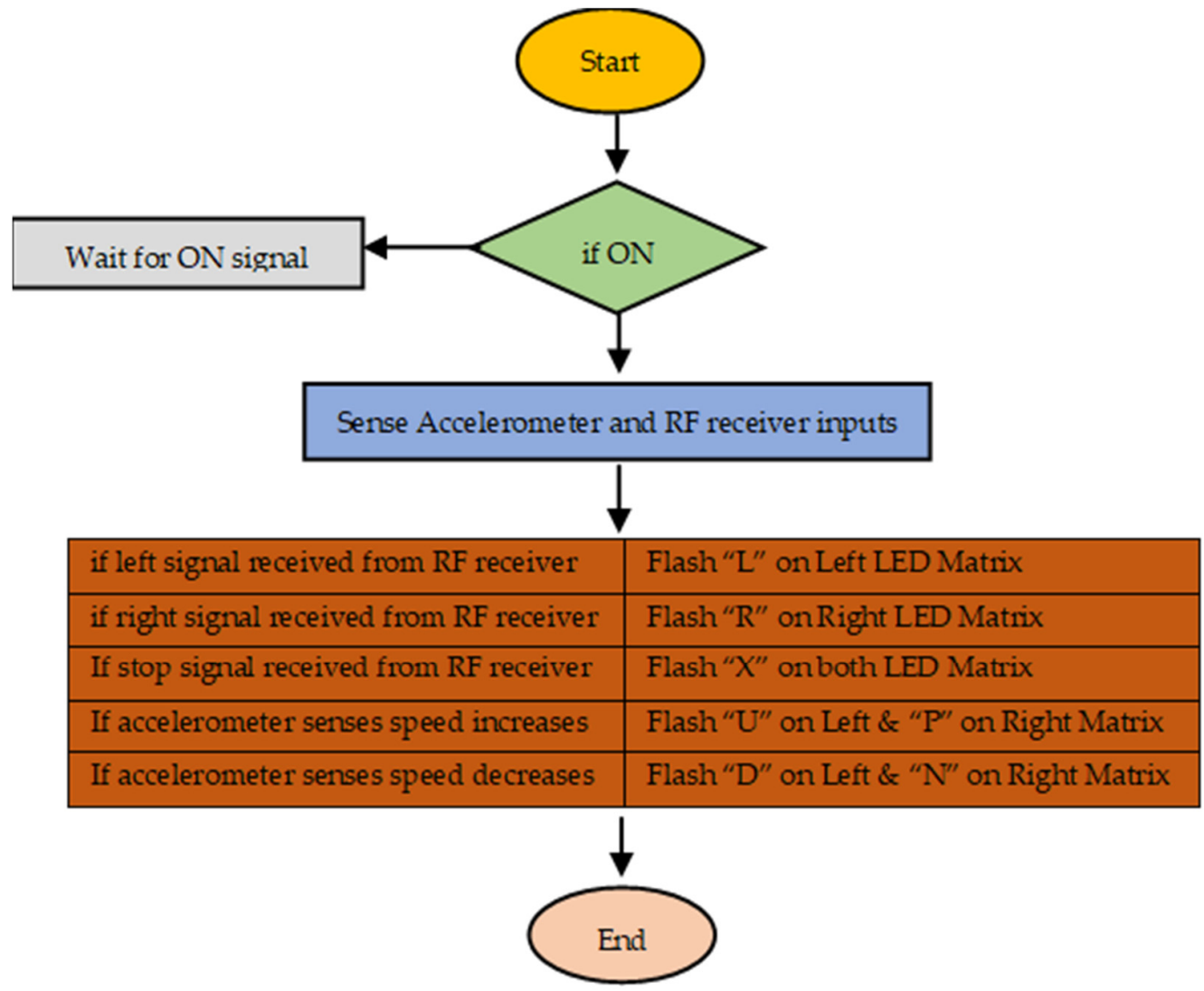

Figure 9. Logic flow diagram.

\section{Comparison of This Smart Helmet with Other Helmets}

There are different types of helmets. Some are traditional helmets that do not have any features similar to this smart helmet, but there are other intelligent helmets present whose features share some similarities with the smart helmet. A brief comparison between these is listed in Table 1. 
Table 1. Comparison of the smart helmet with other helmets.

\begin{tabular}{lccc}
\hline Features & Traditional Helmet [10] & Intelligent Helmet [11] & Smart Helmet \\
\hline Bike Blocking & $\times$ & $\checkmark$ & $\checkmark$ \\
\hline Alcohol Detection & $\times$ & $\checkmark$ & $\checkmark$ \\
\hline $\begin{array}{l}\text { Helmet Worn } \\
\text { Detection }\end{array}$ & $\times$ & $\checkmark$ & $\checkmark$ \\
\hline Accident Detection & $\times$ & $\checkmark$ & $\checkmark$ \\
\hline Acceleration/Deacceleration & $\times$ & $\times$ & $\checkmark$ \\
\hline Rear-view Camera & $\times$ & $\times$ & $\checkmark$ \\
\hline
\end{tabular}

\section{Conclusions}

The proposed helmet can be assembled from off-the-shelf components. Its breakdown into two distinct modules makes installation hassle free and easy. It is expected to reduce traffic accidents. In future, this helmet can be integrated with a GPS and a GSM module to relay the driver's information in case of any emergency. Other proposed helmets have added to the functionality of the basic helmet, but did not address the problem of relaying information to approaching vehicles.

Author Contributions: Conceptualization, M.K.S., S.F. and M.W.; methodology, M.K.S. and S.F.; software, M.K.S.; validation, M.K.S., M.W., M.S.S. and S.F.; formal analysis, M.K.S., M.W., S.F., M.S.S., M.U. and H.B.I.; investigation, M.K.S. and M.W.; resources, M.K.S.; writing-original draft preparation, M.K.S., M.W., S.F., M.S.S., M.U. and H.B.I.; writing-review and editing, M.K.S., M.W., S.F., M.S.S., M.U. and H.B.I.; visualization, S.F.; supervision, M.K.S.; project administration, S.F. and M.W.; funding acquisition, M.K.S., M.W. and S.F. All authors have read and agreed to the published version of the manuscript.

Funding: This research received no external funding.

Data Availability Statement: All the used data is available in cited articles.

Conflicts of Interest: The authors declare no conflict of interest.

\section{References}

1. Koohi, F.; Soori, H. Helmet Use and Its Efficacy on Preventing Motorcycle Injuries: A Systematic Review and Meta-analysis. J. Maz. Univ. Med. Sci. 2019, 28, 198-216.

2. Shaadan, N.; Suhaimi, M.A.; Hazmir, M.; Hamzah, E. Road accidents analytics with data visualization: A case study in Shah Alam Malaysia. J. Phys. Conf. Ser. 2021, 1988, 012043. [CrossRef]

3. Jesudoss, A.; Vybhavi, R.; Anusha, B. Design of smart helmet for accident avoidance. In Proceedings of the 2019 International Conference on Communication and Signal Processing (ICCSP), Chennai, India, 4-6 April 2019; p. 012043.

4. Bhatti, F.; Shah, M.A.; Maple, C.; Islam, S.U. A novel internet of things-enabled accident detection and reporting system for smart city environments. Sensors 2019, 19, 2071. [CrossRef] [PubMed]

5. Davydov, V.; Bezzateev, S. Accident detection in internet of vehicles using blockchain technology. In Proceedings of the 2020 International Conference on Information Networking (ICOIN), Barcelona, Spain, 7-10 January 2020; pp. 766-771.

6. Campero-Jurado, I.; Márquez-Sánchez, S.; Quintanar-Gómez, J.; Rodríguez, S.; Corchado, J.M. Smart Helmet 5.0 for industrial internet of things using artificial intelligence. Sensors 2020, 20, 6241. [CrossRef] [PubMed]

7. Usman, M.; Waseem, M.; Khan, D.; Manan, A.; Ullah, S.; Iqbal, M.M.; Faheem, Z.B. PD Based Cost Effective and Accurate Calorimeter Temperature Control and Measurement System. In Proceedings of the 2020 IEEE International Conference on Sustainable Engineering and Creative Computing (ICSECC), Indonesia, 16-17 December 2020; pp. 189-193.

8. Aatif, M.K.A.; Manoj, A. Smart Helmet Based on IoT Technology. Int. J. Res. Appl. Sci. Eng. Technol. (IJRASET) $2017,5,409-415$.

9. Alvi, U.; Khattak, M.A.K.; Shabir, B.; Malik, A.W.; Muhammad, S.R. A comprehensive study on IoT based accident detection systems for smart vehicles. IEEE Access 2020, 8, 122480-122497. [CrossRef]

10. Goyal, S.; Bedi, P.; Kumar, J. Realtime Accident Detection and Alarm Generation System Over IoT. In Multimedia Technologies in the Internet of Things Environment; Springer: Berlin/Heidelberg, Germany, 2022; Volume 2, pp. 105-126.

11. Tabary, M.; Ahmadi, S.; Amirzade-Iranaq, M.H.; Shojaei, M.; Asl, M.S.; Ghodsi, Z.; Azarhomayoun, A.; Ansari-Moghaddam, A.; Atlasi, R.; Araghi, F. The effectiveness of different types of motorcycle helmets-A scoping review. Accid. Anal. Prev. 2021, 154, 106065. [CrossRef] [PubMed] 